\title{
Fiscal and Monetary Policy: Opportunities and Problems
}

\author{
by WILLIAM E. GIBSON
}

\begin{abstract}
Willam E. Gibson is a Senior Staff Economist for the Council of Economic Advisers. He received a PhD degree from the University of Chicago in 1967. He has served as a Research Fellow at the Federal Reserve Bank of Chicago, as an Assistant Professor of Economics for the University of California at Los Angeles, as a Financial Economist for the Federal Deposit Insurance Corporation, and as a Fellow at the Brookings Institution.
\end{abstract}

This paper was presented at the Annual Conference of College and University Professors at the Federal Reserve Bank of St. Louis on November 3, 1972.

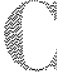
URRENT economic policy in the United States is set in a very prosperous context, but one with considerable challenges implicit for the future. In this presentation 1 shall first describe the progress of the economy to date and then discuss some possible problems in the effective use of fiscal and monetary policy in the future.
\end{abstract}

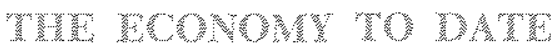

We are now well into what shapes up as a very strong expansion by historical standards. In the four quarters ending with the third quarter of 1972 , our gross national product has grown by over 10 percent, compared with an average rate of 7.2 percent from 1962 to 1971 . Real GNP rose at a 6.4 percent annul rate in the third quarter of 1972 and at a 9.4 percent rate in the second quarter. Over the past four quarters it has risen by 7.2 percent, whereas the average rate of increase from 1962 to 1971 was 3.8 percent.

On the price front, the GNP deflator rose at a 2.4 percent annual rate in the third quarter of 1972 and at a 1.8 percent annual rate in the second quarter. In the past year it has risen by 2.7 percent. This compares with a 3.1 percent average rate from 1962 to 1970 and with a 4.4 percent rate from 1966 to 1970 .

The unemployment rate is presently 5.2 percent and on a downward trend from the 6 percent which prevaled at the end of last year. In addition to the de-

1This presentation has been revised to take into account data available as of December 27, 1972. chine in unemployment, total employment and the labor force have risen at an unusually rapid pace recently. For instance, from the third quarter of 1971 to the third quarter of 1972 , civilian nondefense employment increased by more than 2.6 million. This increase is quite large by historical standards. It is roughly twice as large as the average annual expansion of nondefense employment from 1964 to 1968 , and almost three times as large as the corresponding expansion from 1960 to 1964.

In spite of the large increase in employment, the number of persons unemployed declined by only 222,000 over the same period. This is because the number of persons available for nondefense employment rose by 2.4 million - an unusually large amount. In addition to the normal growth of the labor force of 1.5 million, based on population trends, a rise in labor force participation rates added 0.4 million and a decrease in defense employment added slightly over 0.5 million to the labor force available for nondefense employment

This trend in labor force expansion continued in October, when the labor force rose by 227,000 seasonally adjusted. The full-time civilian labor force rose by over 600,000 persons in October.

At least in part because of such developments in the labor force, the combinations of inflation and unemployment rates attainable from given monetary and fiscal policy combinations do not now conform to those predicted from past experience. As a result, the Administration has continued to emphasize efforts 
to lower unemployment by expanding manpower programs. The Federal Government is presently spending $\$ 5$ billion each year on programs to provide market information, improved training, assistance for relocation, and similar services to workers.

While much has been accomplished, a good deal remains. There is further progress to be made against unemployment, and price increases need to be kept moderate. We are starting with an economic expansion which is vigorous and appears broadly based. The aim of policy is to maintain the present expansion at a high level but within sustainable bounds. That is, denand and output should be kept rising as rapidly as is consistent with avoiding unacceptable inflationary pressures. At the same time the unemployment rate should be reduced further.

To accomplish this, an adroit combination of fiscal and monetary policy will be required so that the expansion neither lags, causing more unemployment, nor quickens excessively, bringing accompanying inflation. In this connection there is a mixed outlook for fiscal and monetary policy.

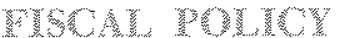

Fiscal policy has been expansionary recently. The Federal deficit was $\$ 23$ billion in fiscal 1971 and $\$ 23.2$ billion in fiscal 1972 , and is estimated to be $\$ 25$ billion in fiscal 1973 (based on outlays of $\$ 250$ billion and receipts of $\$ 225$ billion). More recently, the full employment budget has been in deficit and shows signs of continuing so, particularly if the Administration's proposed spending ceiling (which includes an $\$ 18.5$ billion increase over fiscal 1972) is not approximated.

There are two important, closely related problems in the fiscal policy sphere, one of short-run concern and the second of longer-range import.

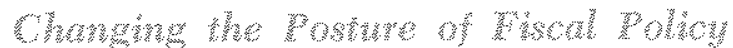

While the expansionary posture of fiscal policy is presently appropriate, the need for a stimulative stance will inevitably recede as the expansion continues to gain momentum. However, it may not be easy to reverse this stance as a result of the institutional context in which fiscal tools are used.

Part of the fiscal armory can be redirected very quickly - these are the so-called automatic stabilizers. These programs expand and contract more or less automatically in response to changes in the pace at which the economy is expanding. Such programs include unemployment compensation, welfare programs, housing subsidies, and the progressive nature of the
Federal tax structure. In addition, since interest rates are generally lower at cyclical troughs than at peaks, the rate at which future benefits of government projects are discounted falls, increasing the present values of many projects and programs. These automatically increase outlays when the economy slows and reduce them as expansion progresses.

While automatic stabilizers make an important contribution to overall stabilization policy, often further fiscal changes are desired, either to add more stimulus or to moderate further a buoyant expansion. This is a much more difficult undertaking, because it is very difficult to change the posture of fiscal policy in either direction quickly.

First of all, new programs require Congressional approval, and this approval must be in a form which in fact provides for the actions sought by the Administration. Bills are sometimes changed in committee or on the floor of Congress in ways which significantly redirect their thrusts.

Similar considerations govern tax legislation. Congress has shown so much reluctance to raise taxes as to make the possibility of a peacetime hike really very questionable. Even lowering taxes takes a long time, and inevitably there are pressures to diverge further from an optimal tax system whenever any taxes are modified.

Transfer payments, although outlays rather than taxes, are (with the exception of automatic stabilizers) subject to the same sorts of forces which slow tax changes. Changes are likely to be a long time coming, and the temptation to embellish a proposed program is likely to be considerable. Further, once recipients become accustomed to the payments (and this may be one of the fastest adjustments in all economic behavior), they and their political representatives will not be anxious to see them withdrawn when the need for stimulus passes. Discretionary changes in transfer payments thus tend to be one-way stabilization tools at best, for use when stimulus is needed. ${ }^{2}$

There is also an offsetting political force which tends to limit the feasibility of transfer payments for stabilization purposes. It might often happen that the quickest and most efficient method of providing stimulus would be to simply mail everyone a check. The

\footnotetext{
2There may be exceptions to this tendency, however. Congress has in recent years extended unemployment benefits beyond the normal 26-week maximum duration on a temporary basis. This extension may in fact not be permanent. If so, the key would seem to lie in the fact that the unemployed are a constantly changing gromp without organized political representation.
} 
distribution of the funds among persons could be determined by any number of criteria, and this might well be more efficient than increasing expenditures on marginal projects or accelerating work on existing projects beyond its most efficient pace. Rightly or wrongly, however, those responsible will likely wish to "get something more" for the money spent, in the interests of "efficiency," even though they might favor a tax cut of the same amount.

In the area of spending, most projects span several years and require long periods to start up and wind down. This inertia is going to make it very hard to change the posture of fiscal policy quickly in coming years.

Spending pressures come from several sources. First, there are some bills proposed long ago by the Administration which have finally been passed by the Congress and which are viewed as fundamental to the Administration's program. Revenue sharing is perhaps the best example of such a bill. This program was an essential part of the President's concept of a New Federalism, and its passage was sought by the Administration. It was designed to usher in a new area of Federal, state, and local cooperation and capitalize on the Federal Government's comparative advantage at tax collection. For a while it also appeared as though it would provide useful fiscal stimulus.

As it happened, the bill was passed in a form generally acceptable to the Administration, but the need for fiscal stimulus is much smaller than it was several quarters ago. This need is likely to diminish further as the program continues.

It also comes at a time when the Federal budget is seriously in deficit and state and local governments are running surpluses, a state of affairs not foreseen when the program was proposed.

Fiscal pressures are also coming from the Congress in the form of bills involving a level of spending far above what the Administration wants. Perhaps the best example here is the Clean Water Bill, which authorizes expenditures exceeding $\$ 24$ billion over as little as three years in order to achieve environmental goals far in excess of reasonable standards.

In addition, the Administration has decided to resist tax increases in 1973 and beyond. This position is based on philosophical considerations, on a firm belief that tax increases in the near future are very unlikely to be enacted, and on a belief that the American people do not want a tax increase.
Accordingly, the scene is set for some friction in the fiscal area. If spending bills continue to be passed and existing programs continue their tendencies toward expansion, something will have to give.

The give will come in the form of vetos, impounding of funds, budget restraint, and/or inflation. (Inflation in most cases could be avoided by an appropriate restrictive monetary policy, but if spending increases are truly substantial such a policy would be difficult to implement because it would imply very high levels of interest rates for a time.)

If spending increases are voted and vetos are overridden the first result will likely be attempts to impound the funds - simply not spend the appropriated funds. If this does not prove effective, the next result will almost certainly be inflation. Later on taxes might be boosted to finance the spending, but inflation will likely have accelerated.

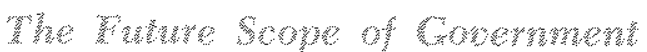

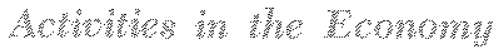

The second main issue on the fiscal side essentially involves the size of the government sector. Studies by the Brookings Institution, the American Enterprise Institute and others show that with the existing tax structure we will be lucky to be able to finance existing programs (with their legislated growth) over the next five years. ${ }^{3}$ There is very little room for any new initiatives unless taxes are raised or other programs are reduced.

The government is getting very large. The proportion of GNP that runs through government budgets has been steadily rising. In 1956, Federal, state, and local nondefense spending was 15 percent of GNP. In 1971 it was 23.6 percent of what full employment GNP would have been. The proportion has increased in every year but one since 1956.

Since it is virtually unimaginable that a year could go by without the development of pressing new "needs" to be met by the Government, the fiscal area is likely to witness considerable tension for some years to come.

Some fundamental decisions are going to have to be made on the appropriate role of government and how extensive its participation in the economy should

BCharles L. Schultze et al, Setting National Priotities; The 1973 Budget (Washington, D.C.: The Brookings Institution, 1972 ) and David I. Ott et al., Nixon, McGovern, and the Federal Budget (Washington, D.C.: Amlerican Enterprise Institute, 1972). 
be. These decisions will have to be made by whoever is President.

\section{MOME M}

Monetary policy will also have an important role to play in coming years if we are to attain a sustainable high-level of expansion. While it is almost trivial to state that monetary policy must be neither too rapid nor too slow when account is taken of fiscal policy, this turns out to be much easier said than done.

There is of course first a problem in knowing what rate of monetary growth is appropriate. This problem should not be minimized, but it should be the subject of a separate discussion all its own. In any case, there have been instances in the past where nearly all theoretical approaches were in agreement as to the appropriate monetary course. However, the problem came in the execution of such a policy.

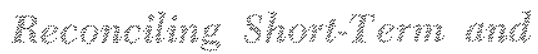

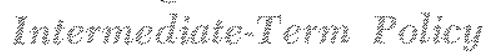

Over the long run, attaining an appropriate monetary growth rate has not been a serious problem. Historically, growth rates have not averaged extreme levels over periods of three years and longer. And even if they did, the economy could probably adjust to these extreme rates more satisfactorily the less acute were the short-run variations around the trend. The problem for monetary policy has been to make week-to-wcek and month-to-month policy compatible with quarter-to-quarter and year-to-year policy.

The first challenge for policymakers is identifying true nonseasonal variation in monetary aggregates. Seasonal adjustment of economic time series is a complex process, and the finest available techniques are used on the money stock. Still, some traces of seasonal regularity occasionally appear in seasonally adjusted data. As an example, from 1967 to 1971 the average rate of growth of seasonally adjusted $M_{1}$ (currency plus demand deposits adjusted, based on quarterly averages) in the fourth quarter was below those for both the second and third quarters. In 1966 it was higher than the third quarter $(0.2$ percent versus -0.7 percent) but both were far below rates for the first and second quarter. This pattern held for 1972 as well. While this example is not by itself sufficient evidence of inadequate seasonal adjustment, it does suggest that considerable care be exercised in adjusting for seasonal variation.

Even with perfect seasonal adjustment, it would still be very difficult to maintain a specified monetary growth rate from week to week. Although there is considerable predictability in the money stock, data on money are available only with a one week lag, so that precise weekly control is not entirely feasible.

Furthermore, it is not clear that such precise shortrun control is actually necessary. There is widespread professional belief that extreme rates of monetary growth over periods as long as two quarters will not seriously hurt the economy if followed by an equal period of offsetting growth. That is, this view holds that if money grows at a 10 percent rate for two quarters and then at a 2 percent rate for the subsequent two quarters, the effects will be roughly the same within a few quarters as if the rate had been 6 percent throughout. ( $\mathrm{I}$ believe that the selection of a two-quarter period is based largely on intuition, but this is more than can be said for, say, a four-quarter period. Whatever the length of the period is, it is likely longer than a month, even though some observers see scope for fine tuning with monthly variations in monetary growth).

There is thus room for swings in the money stock over brief periods without really compromising sixmonth period goals. The problem, however, is in maintaining compatibility between week-to-week behavior and multi-quarter goals. The longer the weekly series diverges from a desired path, the longer and/or sharper will be the required offsetting policy.

This might not appear to be a severe problem, but it has the potential to be one for at least two reasons. First, it is difficult to establish trends from looking at weekly data due to the random fluctuations of any statistical series over a short period. If the series is running below target, it is easy to believe that without any policy actions it will soon hit the target path.

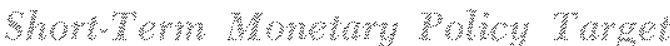

Second, since the money stock cannot be controlled over a week, a two-tiered intermediate target scheme has been established. The ultimate goals of monetary policy are formulated in terms of GNP, employment, output, prices, the balance of payments, and the like. But since these are somewhat remote from the instruments under Federal Reserve control, an intermediate target variable is used. Such a variable ideally stands somewhere in the transmission process and is more or less closely influenced by the Federal Reserve. Various variables have been used for this purpose in the past, including member bank borrowings from the Federal Reserve, free reserves, and, most of all, market interest rates. 
From the 1950s until early 1970 , various short-term interest rates were the intermediate target (sometimes sharing center stage with free reserves). In 1970 the monetary growth rate superseded interest rates as the intermediate target. But since the growth rate of money could not be controlled weekly, the System Open Market Account Manager was given a daily or weekly Federal funds rate target to establish in order to reach this desired monetary growth rate. Thus, short-term interest rates continued to be the day-today operating target. While the emphasis of policy in some sense had shifted to monetary aggregates, policy still depended on the Federal Reserve System's ability to predict the relationship between interest rates and the monetary growth rate as well as its ability to influence market interest rates.

When the problems of identifying a trend in money, identifying a trend in interest rates, predicting the effect of the latter on the former, and controlling interest rates are combined, there is considerable room for deviation from a target monetary growth rate.

This was seen perhaps most vividly in 1971. After the first two months of the year, recorded monetary policy was largely directed at lowering the monetary growth rate. Federal Reserve predictions implied that the rate should have fallen in the second quarter, based on prevailing Federal funds rates. Yet the money stock rose at a 10.2 percent annual rate from December to June - much faster than desired or predicted. Essentially the reverse occurred in the second half, and the money stock rose at a 0.8 percent rate after July.

In 1972 the Federal Reserve moved further to increase the compatibility of weekly movements and quarterly targets by adopting reserves available to support private nonbank deposits (RPDs) as its daily operating target. There is not a perfectly stable relationship between RPD growth and monetary growth, and we may be able to do better by using the monetary base or something else. But this connection is much closer than that between the Federal funds rate and the monetary growth rate. The adoption of RPDs therefore marks an important step toward more manageable and accurate monetary policy.

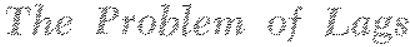

This is especially important in light of the lags in the effect of monetary policy on the economy. While these lags have long been widely recognized, it was generally thought that to the extent they are predictable, policy could be operated to take account of these lags, and thus the monetary growth rate could be managed. Some recent work in this area suggests that this too may be easier said than done. ${ }^{4}$ Even without uncertainty about the length and variability of the lags in the effect of monetary changes, a full offsetting of past swings in monetary growth can easily require huge oscillating swings in the monetary rate, with accompanying perturbation for capital markets. In some cases, the system can even become explosive, requiring alternately increasing opposite rates of growth from quarter to quarter. When uncertainty is added, the whole business is extremely hazardous.

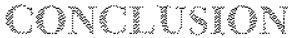

The moral here, I think, is that monetary policy is not really appropriate for month-to-month or quarterto-quarter fine tuning the way some people thought a few years ago. Probably its optimal role is to provide a generally expansive, restrictive, or in some sense neutral environment over a period of at least several quarters. Similar considerations hold for fiscal policy. If we can coordinate the two to avoid sharp shifts, we can probably minimize all quarterly fluctuations in GNP over a period of several quarters and years. This would be a very sizable accomplishment.

4Philip Cagan and Anna J. Schwartz, "How Feasible is a Flexible Monetary Policy" (Paper presented at a conference in honor of Milton Friedman, Charlottesville, Virginia, October 20,1972 ).

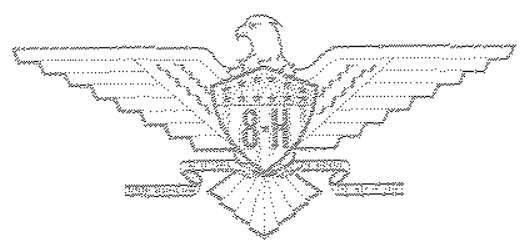

